\title{
Control of Doubly Fed Induction Generator with Maximum Power Point Tracking for Variable Speed Wind Energy Conversion Systems
}

\author{
Ibrahim Yaichi ${ }^{1 *}$, Abdelhafid Semmah¹, Patrice Wira² \\ 1 Department of Electrical Engineering, Faculty of Electrical Engineering, Djillali Liabes University, University campus, P. O. B. 89, \\ 022000 Sidi Bel Abbes, Algeria \\ ${ }^{2}$ Institut de Recherche en Informatique, Mathématiques, Automatique et Signal (IRIMAS), Université de Haute Alsace, 61 Albert \\ Camus Street, 68093 Mulhouse, France \\ * Corresponding author, e-mail: ibrahimyaichi@gmail.com
}

Received: 08 April 2019, Accepted: 16 July 2019, Published online: 04 November 2019

\begin{abstract}
In this paper, a Direct Power Control (DPC) based on the switching table and Artificial Neural Network-based Maximum Power Point Tracking control for variable speed Wind Energy Conversion Systems (WECS) is proposed. In the context of wind energy exploitation, we are interested in this work to improve the performance of the wind generator by controlling the continuation of the Maximum Power Point Tracking (MPPT) using the Artificial Neural Network (ANN). The results obtained show the interest of such control in this system. The proposed Direct Power Control strategy produces a fast and robust power response, also the grid side is controlled by Direct Power Control based a grid voltage position to ensure a constant DC- link voltage. The THD of the current injected into the electric grid for the Wind Energy Conversion Systems with Direct Power Control is shown in this paper, the THD is lower than the $5 \%$ limit imposed by IEEE STANDARDS ASSOCIATION. This approach Direct Power Control is validated using the Matlab/Simulink software and simulation results can prove the excellent performance of this control as improving power quality and stability of wind turbine.
\end{abstract}

Keywords

Doubly Fed Induction Generator, Maximum Power Point Tracking, Proportional-Integral, Direct Power Control, Artificial Neural Network, Phase Locked Loop

\section{Introduction}

The renewable energy market has grown considerably in recent years. Intensive consumption of electrical energy, rising hydrocarbon prices and concern for the environment have led several countries to initiate national and international programs to produce electricity from renewable resources [1]. This change has been accompanied by the liberalization of the electricity market and the proliferation of renewable production, in particular, wind power generation $[2,3]$. The latter is characterized by its random and intermittent nature which is often at the origin of serious problems related to the stability of the electricity network $[4,5]$.

For a wind turbine application where the use of DFIG is intense, the rotational speed of the rotor is adjusted according to the wind speed. Indeed, the DFIG allows operation in hypo synchronous and hypersynchronous generator. The interest of the variable speed for a wind turbine is to be able to work on a wide range of wind speeds, which makes it possible to draw the maximum possible power, for each wind speed [6].

Artificial Neural Network (ANN) techniques are increasingly being used as an alternative to other conventional approaches or as components in integrated systems. They have been used to solve complex practical problems in various fields. ANN techniques have the following characteristics: learning from examples, fault tolerances in the sense that they are able to process noisy and incomplete data, ability to deal with non-linear problems, and once formed, they can perform high-speed forecasting and generalization [7].

Artificial intelligence systems are developed and deployed in many applications, mainly because of their symbolic reasoning, flexibility, and explanatory capabilities. Artificial intelligence has been used and applied in different sectors, such as engineering, economics, 
medicine, the military, etc. It has also been applied for modeling, identification, optimization, forecasting, and control of complex systems (and/or) non-linear.

To get the optimum performance of the wind turbine at variable speed wind, it is necessary to extract the MPPT using different MPPT controllers. The purpose of this paper discusses and compares advantages, efficiency, and accuracy for the chosen MPPT techniques in wind conversion system (Artificial Neural Network (ANN) and Proportional-Integral (PI)). Matlab/Simulink is used to design and simulate the wind system turbine and to compare selected MPPT controller's performances.

The first application developed was the control of an electric machine and the control structure was known as Direct Torque Control (DTC). In this case, the stator flux and the electromagnetic torque of the machine are controlled without any modulation block [8].

For thirty years, several control strategies have been developed to perform a decoupled control of the induction machine. These methods called "vector controls" provide dynamic performance equivalent to that obtained by the DC machine [7, 8]. In recent years, the development of new signal processing techniques has enabled the realization of much more advanced control structures. The most recent steps in this direction are those grouped under the direct control of torque (DTC) and power (DPC). The control Synoptics have evolved in the sense of improving certain aspects such as the minimization of the influence of the parameters of the machine. The principle of direct control, including torque, was proposed in 1986 by Takahashi and Noguchi [9], and it was developed later for other applications. The aim was to eliminate the modulation block and internal loops by replacing them with a switchboard whose inputs are the errors between the reference values and the measurements made. In this control technique, the controlled variables are the active and reactive instantaneous powers.

This work aims to study and apply the DPC control technique to control the operation in the optimal conditions of the Wind Energy Conversion System.

The goal of this control was to ensure the sampling of sinusoidal currents while guaranteeing a unit power factor with decoupled control of the active and reactive powers.

This work is divided into two parts: The first part is dedicated to the modeling of the kinetic-mechanical energy conversion system (wind, blades, turbine, multiplier, ...) and its MPPT control.

The second part is intended for modeling and DPC control of the mechanical-electrical conversion system (the wind generator). The last part presents the modeling of the power converter associated with the wind generator. The entire system will be validated by simulation using Matlab/Simulink software. From the result obtained, the DPC control makes it possible to obtain high dynamic performances with a simple structure.

\section{Description of a Wind Energy Conversion System}

The turbine converts the kinetic energy of the wind into mechanical energy and the total kinetic power available on the wind turbine is given by:

$P=\frac{1}{2} \rho S v^{3}$.

For wind turbines, the energy extraction coefficient $C_{p}$ that depends on both the wind speed and the rotational speed of the turbine is generally defined in the range 0.35-0.59 [10].

Thus, the DFIG transforms the latter into electrical energy. The converters are used to transfer the maximum energy delivered by the wind turbine to the grid depending on the wind speed [11].

$$
\begin{aligned}
C_{p}(\beta, \lambda)= & (0.5-0.0167(\beta-2)) \\
& \sin \left[\frac{\pi(\lambda+0.1)}{18.5-0.3(\beta+2)}-0.00184(\lambda-3)(\beta-2)\right]
\end{aligned}
$$

\section{The MPPT controllers}

Wind turbines used for the production of electricity must allow producing a maximum of power by making the best use of the available energy in the wind. This is why many control systems of the wind turbine, acting at the mechanical part via the wedge angle of the blades or electric by the control of the electrical machine via the power electronics, are developed to maximize energy conversion.

\subsection{The Proportional-Integral controller}

This control strategy consists of adjusting the electromagnetic torque of the generator to set the mechanical rotation speed at a reference speed making it possible to extract the maximum power from the turbine [8]. Thus, a servo-control of the rotation speed of the DFIG must be performed. For a given operating point (fixed wind speed), the mechanical power is maximum if the maximum value of the coefficient $C_{p}$ is reached. This is obtained if the relative speed $\lambda$ is equal to its optimum value $\lambda_{\text {opt }}$. Therefore, the reference rotation speed of the DFIG $\Omega_{g}^{*}$ is obtained by Eq. (3):

$\Omega_{g}^{*}=G \Omega_{t}^{*}$ 
with:

$$
\Omega_{t}^{*}=\frac{\lambda_{o p t} V}{R} .
$$

The reference electromagnetic torque ${ }_{g}^{*}$ allowing to have a speed of rotation $\Omega_{g}$ equal to its reference value $\Omega_{g}^{*}$ obtained at the output of the speed regulator.

A Proportional-Integral type regulator (PI) thus serves to control the speed of rotation and to attenuate the effect of the torque of the DFIG $C_{g}$ considered as a disturbance. The block diagram of the MPPT control with servo-control of the mechanical speed of rotation is shown in Fig. 1.

\subsection{The Artificial Neural Network controller}

Artificial Neural Networks are a technique that makes it possible to learn slightly numerically than symbolically and that is based on arithmetic rather than logic (rules of production). They have been used primarily for pattern recognition, speech recognition, optimization, etc., but their learning capabilities make them interesting in the field of process control and control as well [12].

The back-propagation algorithm in its basic form uses the gradient descent technique, which is among the simplest, but it is not very efficient in the general case because it uses little information on the surface of the gradient the mistake. In the literature, there is a large amount of more sophisticated techniques, among these techniques the Levenberg-Marquardt algorithm. This last algorithm will be used in our work for its speed of computation compared to the classic back-propagation algorithm [13].

The algorithm consists, in its first step, in propagating forward inputs until an output calculated by the network. The second step compares the calculated output to the actual known output. The parameters (weight) are then modified such that, at the next iteration, the error made between the calculated output and the actual output is minimized.

Thus, for the conventional structure of the network with a layer of hidden neurons, it is necessary to determine

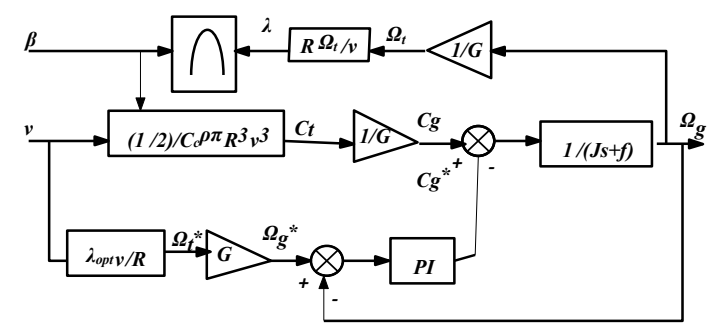

Fig. 1 MPPT control of DFIG (PI) the optimal number of these by a selection procedure. It is the same for the number of layers. However experience shows that a single hidden layer is also sufficient.

The proposed neuron network architecture for MPPT consists of a single multilayer neuron network MLP (multi-layered perceptron) with a single hidden layer, using a Levenberg-Marquardt back-propagation algorithm to perform the learning. Simulations are carried out to evaluate the proposed techniques in terms of trajectory tracking to maximize the power extracted from the wind $[14,15]$.

We used the Levenberg-Marquardt algorithm in our work for its speed of computation compared to the classic back-propagation algorithm.

The back-propagation algorithm is used to train the neural networks. As soon as the training procedure is over, the neural network gives almost the same output pattern for the same or nearby values of input. This tendency of the neural networks which approximate the output for new input data is the reason for which they are used as intelligent systems.

From the tests carried out on the various structures, we found that the most judicious choice was to take multilayer neuron network architecture with structure: 1-10-1, that is to say 3-layer MLP, an input layer containing one neuron, a single hidden layer containing 10 neurons and an output layer containing one neuron.

This work is devoted to the application of neural control to control the speed of rotation and to attenuate the effect of the DFIG $C_{g}$ couple considered as a disturbance. The proposed control scheme ANN is shown in Fig. 2.

In this application the structure of the MPPT neural control of the turbine is shown in Fig. 3, whose PI controller is replaced by ANN neural controller.

In this algorithm, the speed control is realized using the two types of regulators (PI, ANN). The simulation results for the two types of regulators inherent in this algorithm are shown in Figs. 4-8, respectively. These results show that better control for closed loop ANN is obtained in transient and steady state conditions.

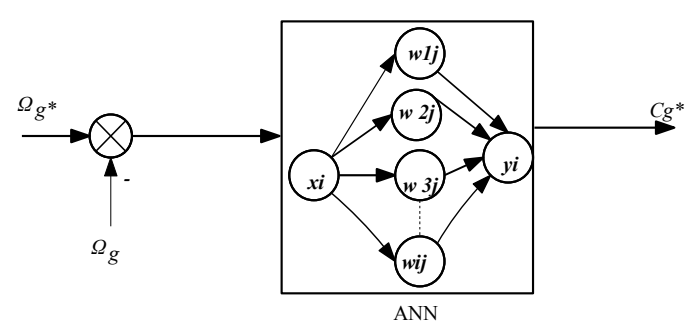

Fig. 2 MLP proposed scheme 


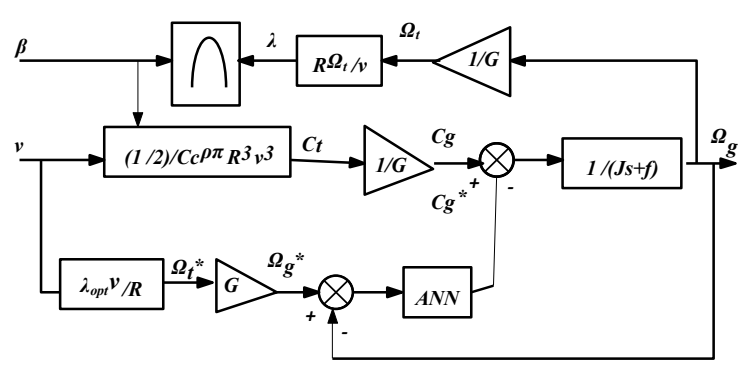

Fig. 3 MPPT control of DFIG (ANN)

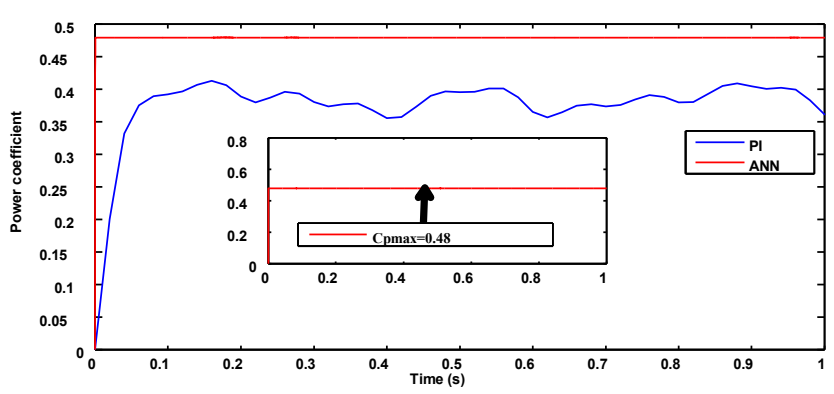

Fig. 4 Power coefficient of DFIG (MPPT)

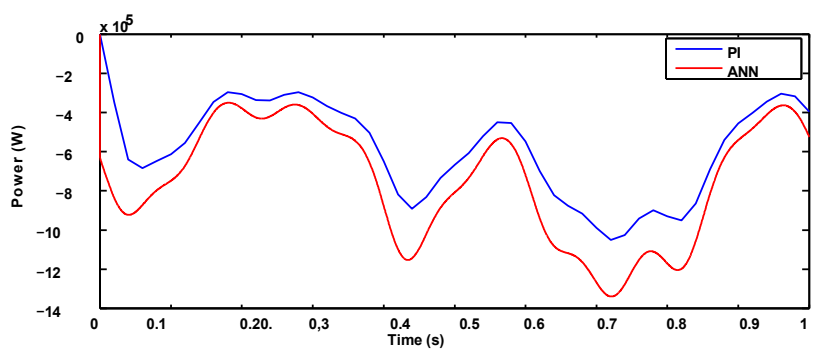

Fig. 5 Comparison between aerodynamic powers obtained with the structure of ANN and PI

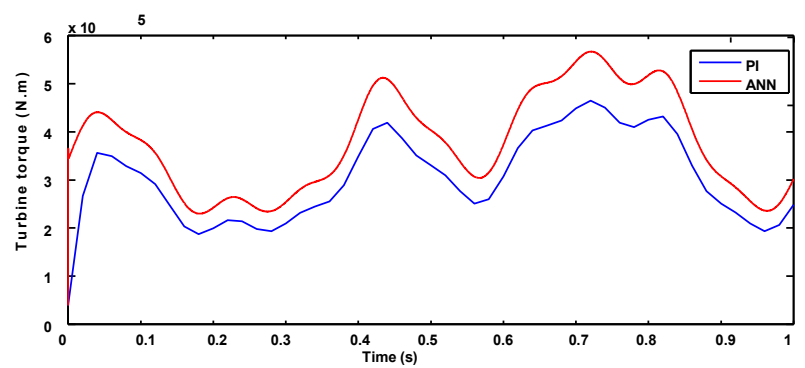

Fig. 6 Comparison between turbine torques obtained with the structure of ANN and PI

Fig. 4 shows the power coefficient of the wind turbine as a function of time, it can be seen that the value of the power coefficient reached the maximum value $\left(C_{p \max }=0.48\right)$ for the control ANN.

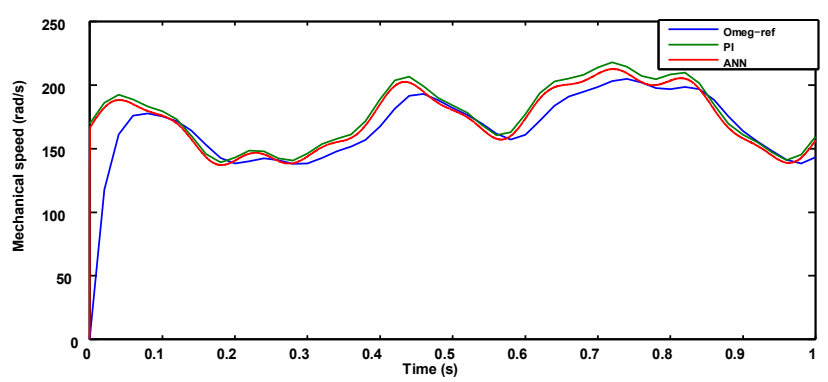

Fig. 7 The allure of mechanical speed for DFIG

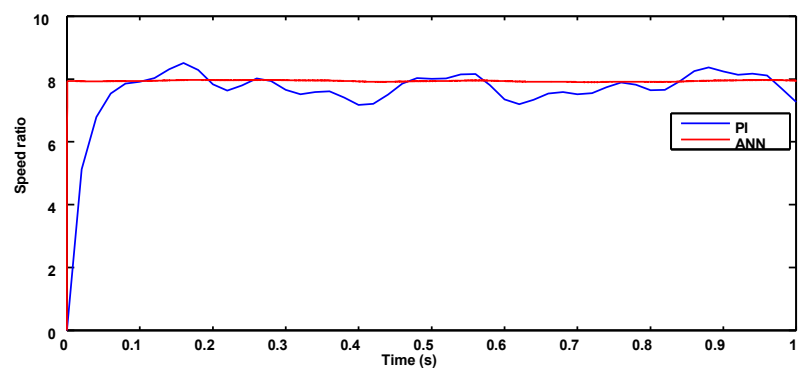

Fig. 8 The allure of the speed ratio for DFIG

Extraction of maximum wind power is always complete (Fig. 5) for ANN control with maximum torque (Fig. 6).

The result obtained in Fig. 7 shows the good static and dynamic performances, good continuation of the controlled setpoint (mechanical speed) and a desirable response time offered by the regulator ANN compared to PI.

In this case, a maximum power coefficient and an optimal speed ratio have been maintained as shown in Fig. 4 and Fig. 8. It can be seen that energy efficiency is almost optimal for the entire range of wind speeds.

Finally, the results obtained for the MPPT control strategy (ANN) show good static and dynamic performance, a desirable response time offered by this technique. This justifies the choice of the MPPT method for controlling the turbine.

\section{Modeling and vector control of the DFIG}

The modeling of the DFIG is described in the Park reference system. Equations (5)-(7) describe the overall modeling of the generator $[16,17]$.

$$
\left\{\begin{array}{l}
V_{d s}=R_{s} I_{d s}+\frac{d \varphi_{d s}}{d t}-\omega_{s} \varphi_{q s} \\
V_{q s}=R_{s} I_{q s}+\frac{d \varphi_{q s}}{d t}-\omega_{s} \varphi_{d s} \\
V_{d r}=R_{r} I_{d r}+\frac{d \varphi_{d r}}{d t}-\left(\omega_{s}-\omega_{r}\right) \varphi_{q r} \\
V_{q r}=R_{r} I_{q r}+\frac{d \varphi_{q r}}{d t}-\left(\omega_{s}-\omega_{r}\right) \varphi_{d r}
\end{array}\right.
$$




$$
\begin{aligned}
& \left\{\begin{array}{l}
\varphi_{d s}=L_{s} I_{d s}+M I_{d r} \\
\varphi_{q s}=L_{s} I_{q s}+M I_{q r} \\
\varphi_{d r}=L_{r} I_{d r}+M I_{d s} \\
\varphi_{q r}=L_{r} I_{q r}+M I_{q s}
\end{array}\right. \\
& J \frac{d \Omega}{d t}=C_{e m}-C_{r}-f \Omega
\end{aligned}
$$

The electromagnetic torque is also expressed as a function of currents and flux by:

$$
C_{e m}=\frac{3}{2} \frac{M}{L_{s}} p\left(\varphi_{q s} I_{d r}-\varphi_{d s} I_{q r}\right) \text {. }
$$

To be able to control the electricity production of the wind turbine easily, we will carry out an independent control of the active and reactive powers by establishing the equations which link the values of the rotor voltages, generated by an inverter, with the active and reactive stator powers [18, 19].

For obvious reasons of simplification, a reference $d-q$ linked to the rotating field and a stator flux aligned with the axis $d$ have been adopted, consequently [20, 21]:

$\varphi=\varphi_{d s}=\varphi_{s}$ and $\varphi_{q s}=0$.

Equation (4) of the flux becomes:

$$
\left\{\begin{array}{l}
\varphi_{s}=L_{s} I_{d s}+M I_{d r} \\
0=L_{s} I_{q s}+M I_{q r}
\end{array} .\right.
$$

If we assume that the electrical network is stable, this leads to a constant stator flux $\varphi_{s}$. Besides, the stator resistance can be neglected since this is a realistic assumption for the generators used in the wind turbine. Starting from these considerations, we obtain $[22,23]$ :

$$
\left\{\begin{array}{l}
V_{d s}=0 \\
V_{q s}=V_{s}=\omega_{s} \varphi_{s}
\end{array} .\right.
$$

In the two-phase reference, the active and reactive stator powers of a DFIG are written according to:

$$
\left\{\begin{array}{l}
P_{s}=V_{d s} I_{d s}+V_{q s} I_{q s} \\
Q_{s}=V_{q s} I_{d s}-V_{d s} I_{q s}
\end{array} .\right.
$$

Adaptation of this Eq. (12) to simplifying hypotheses gives [24]:

$$
\left\{\begin{array}{l}
P=-V_{s} \frac{M}{L_{s}} i_{q r} \\
Q=-V_{s} \frac{M}{L_{s}} i_{d r}+\frac{V_{s}^{2}}{L_{s} \omega_{s}}
\end{array} .\right.
$$

To control the DFIG, expressions are established showing the relationship between the currents and the rotor voltages that will be applied to it.

$$
\begin{aligned}
& V_{d r}=R_{r} I_{d r}+\left(L_{r}-\frac{M^{2}}{L_{s}}\right) \frac{d I_{d r}}{d t}-g\left(L_{r}-\frac{M^{2}}{L_{s}}\right) \omega_{s} I_{q r} \\
& V_{q r}=R_{r} I_{q r}+\left(L_{r}-\frac{M^{2}}{L_{s}}\right) \frac{d I_{q r}}{d t}+g\left(L_{r}-\frac{M^{2}}{L_{s}}\right) \omega_{s} I_{d r}+g \frac{M V_{s}}{L_{s}}
\end{aligned}
$$

\section{Direct Power Control strategy \\ 5.1 DPC of the DFIG}

The principle of the DPC consists in selecting a sequence of switching commands $\left(S_{a}, S_{b}, S_{c}\right)$ of the semiconductors, from a switching table [25]. The selection is made on the basis of the errors between the references of the active and reactive powers and their real values, provided by two hysteresis comparators of digitized outputs $H_{p}$ and $H_{q}$ respectively, as well as on the sector (zone) in which the vector of the rotor flux is $[26,27]$.

The DPC control structure of the DFIG is represented by the block diagram of Fig. 9.

\subsection{Estimation of active and reactive powers}

Instead of measuring the powers on the line, we capture the rotor currents and estimate $P_{s}$ and $Q_{s}$. This approach gives early control of the powers in the stator windings [28, 29]:

$$
\left\{\begin{array}{l}
P_{s}=-\frac{3}{2} \frac{M}{\sigma L_{s} L_{r}} V_{s} \varphi_{r \beta} \\
Q_{s}=\frac{3}{2}\left(\frac{V_{s}}{\sigma L_{s}} \varphi_{s}-\frac{V_{s} M}{\sigma L_{s} L_{r}} \varphi_{r \alpha}\right)
\end{array}\right.
$$

where:

$$
\left\{\begin{array}{l}
\varphi_{r \alpha}=\sigma L_{r} i_{r \alpha}+\frac{M}{L_{s}} \varphi_{s} \\
\varphi_{r \beta}=\sigma L_{r} i_{r \beta} \\
\left|\overrightarrow{\varphi_{s}}\right|=\frac{\left|\overrightarrow{V_{s}}\right|}{\omega_{s}} \\
\sigma=1-\frac{M^{2}}{L_{s} L_{r}}
\end{array} .\right.
$$

By introducing the angle $\delta$ between the stator and rotor flux vector, $P_{s}$ and $Q_{s}$ become $[30,31]$ :

$$
\begin{aligned}
& \left\{\begin{array}{l}
P_{s}=-\frac{3}{2} \frac{M}{\sigma L_{s} L_{r}} \omega_{s}\left|\varphi_{s}\right|\left|\varphi_{r}\right| \sin \delta \\
Q_{s}=\frac{3}{2} \frac{\omega_{s}}{\sigma L_{s}}\left|\varphi_{s}\right|\left(\frac{M}{L_{r}}\left|\varphi_{r}\right| \cos \delta-\left|\varphi_{s}\right|\right)
\end{array}\right. \\
& \left\{\begin{array}{l}
\frac{d P_{s}}{d t}=-\frac{3}{2} \frac{M}{\sigma L_{s} L_{r}} \omega_{s}\left|\varphi_{s}\right| \frac{d\left|\varphi_{r}\right| \sin \delta}{d t} \\
\frac{d Q_{s}}{d t}=\frac{3}{2} \frac{M \omega_{s}}{\sigma L_{s} L_{r}}\left|\varphi_{s}\right| \frac{d\left(\left|\varphi_{r}\right| \cos \delta\right)}{d t}
\end{array}\right.
\end{aligned}
$$




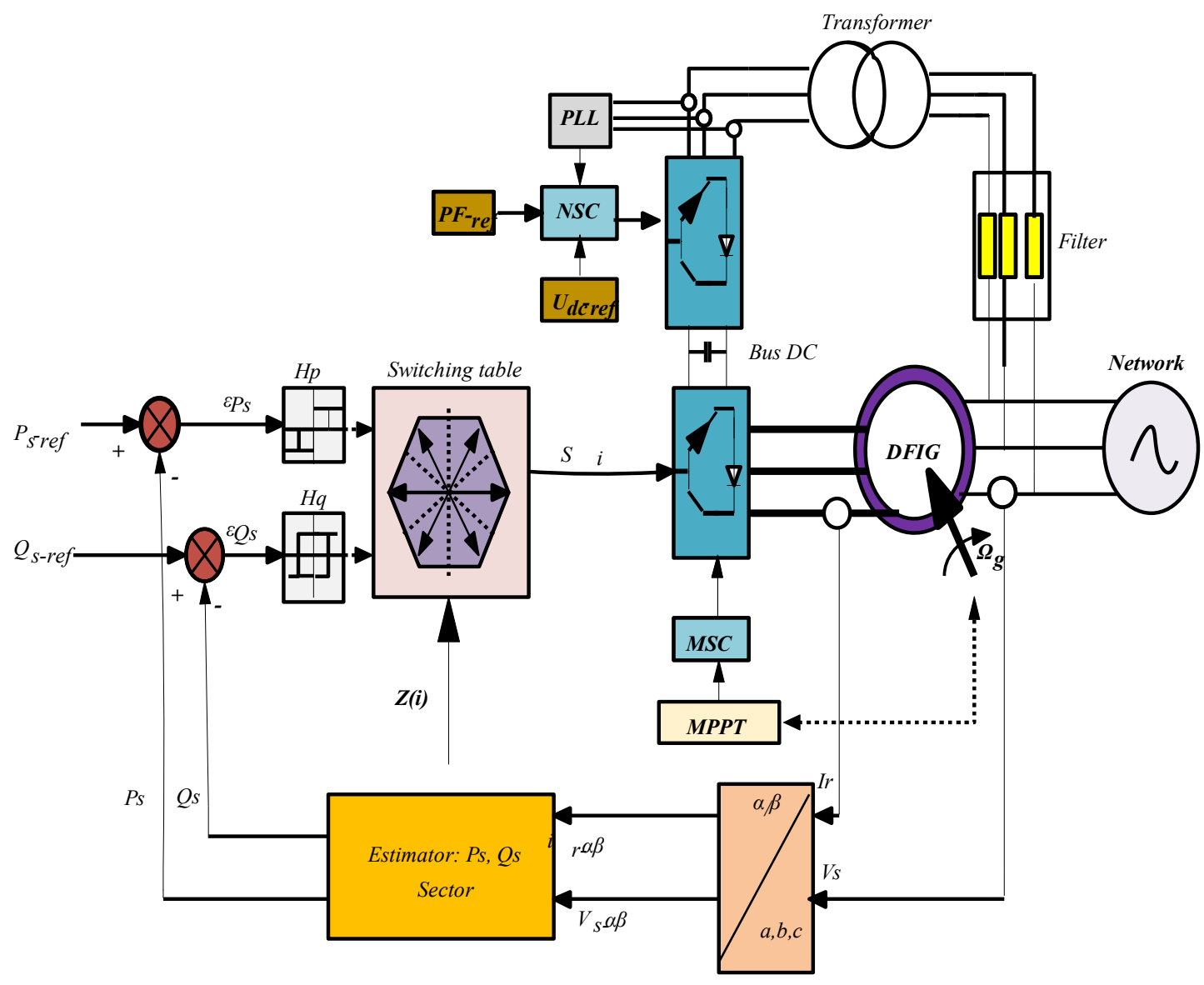

Fig. 9 Configuration of the DPC of the DFIG

To ensure that the inverter has a stable DC voltage, an intermediate DC voltage bus is created [32]. It is managed by a rectifier fed through a transformer by the threephase system of the supposedly symmetrical electrical network with imposed and constant amplitude and frequency voltages. After straightening a filter stage is necessary in order to stabilize the voltage [33, 34].

The control of the static converter connected to the "NSC" network consists in regulating the intermediate DC bus regardless of the power generated by the variable frequency conversion system while ensuring a unit Power Factor (PF) on the $\mathrm{AC}$ side. While the static converter connected to the rotor of the DFIG "MSC" is used for the management of the active and reactive powers of the machine $[33,35]$.

To determine the angles required for Park transformations for stator magnitudes $\left(\theta_{s}\right)$ and for rotor magnitudes $\left(\theta_{r}\right)$, we used a Phase-Locked Loop (PLL) as shown in Fig. 10. This PLL makes it possible to estimate the frequency and amplitude of the network voltage accurately.

The wind turbine parameters are presented in Table 1. Table 2 presents the main parameters of the DFIG simulation model.

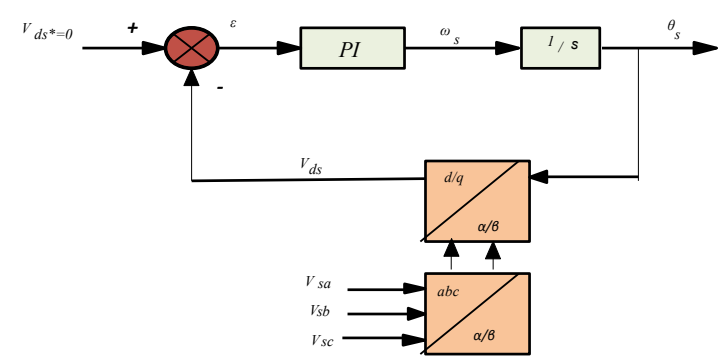

Fig. 10 Phase locked loop diagram

Table 1 Parameters of the wind turbine (1.5 MW)

\begin{tabular}{lcc}
\hline Parameters & Unites & Values \\
\hline Number of blades & {[]} & 3 \\
The power coefficient $C_{p \max }$ & {[]} & 0.59 \\
Rotor radius $R$ & {$[\mathrm{~m}]$} & 35.25 \\
Speed multiplier gain $G$ & {[]} & 90 \\
The density of the air $\rho$ & $\mathrm{kg} / \mathrm{m}^{3}$ & 1.225 \\
Moment of total inertia $J$ & $\mathrm{Kg} \cdot \mathrm{m}^{2}$ & 1000 \\
\hline
\end{tabular}

\section{Simulation Results}

The simulation results are shown in Figs. 11-13. The simulation is performed using Matlab/Simulink software. 
Table 2 Doubly fed induction generator parameters

\begin{tabular}{lccc}
\hline & DFIG parameters & & \\
Parameter name & Symbol & Value & Unit \\
\hline Rated power & $P_{n}$ & 1.5 & $\mathrm{MW}$ \\
Rated current & $I_{n}$ & 1900 & $\mathrm{~A}$ \\
Rated DC-Link voltage & $U_{\mathrm{DC}}$ & 1200 & $\mathrm{~V}$ \\
Stator rated voltage & $V_{s}$ & $398 / 690$ & $\mathrm{~V}$ \\
Stator rated frequency & $f$ & 50 & $\mathrm{~Hz}$ \\
Rotor inductance & $L_{r}$ & 0.0136 & $\mathrm{H}$ \\
Stator inductance & $L_{s}$ & 0.0137 & $\mathrm{H}$ \\
Mutual inductance & $M$ & 0.0135 & $\mathrm{H}$ \\
Rotor resistance & $R_{r}$ & 0.021 & $\Omega$ \\
Stator resistance & $R_{s}$ & 0.012 & $\Omega$ \\
Number of pair of poles & $p$ & 2 & - \\
\hline
\end{tabular}

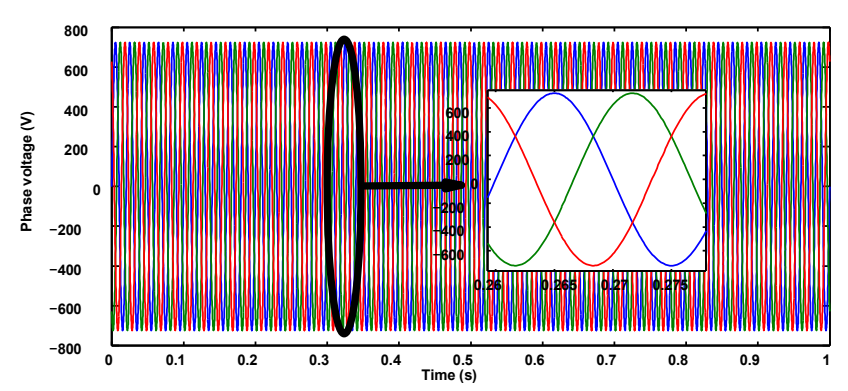

Fig. 11 Voltage of the three network phases

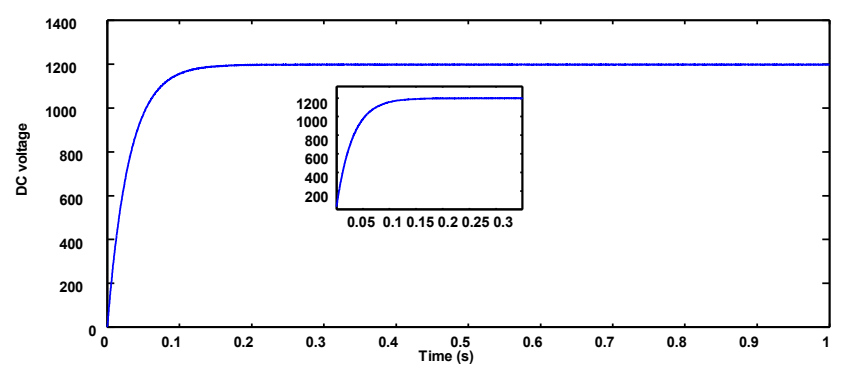

Fig. 12 DC bus voltage of DFIG

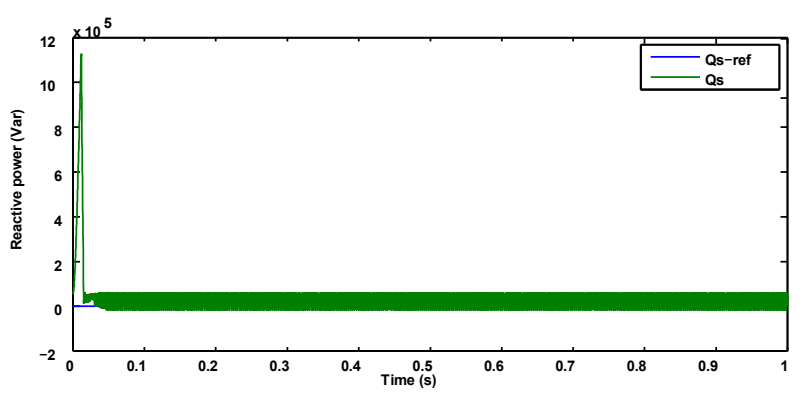

Fig. 13 DPC strategy response

Fig. 11 illustrates the voltage of the three network phases; the results obtained show that the currents have sinusoidal.

To control the relay functionality, two hysteresis comparators and one switching table are used. The DC bus voltage is controlled to provide the reference of the active power, on the other hand the reference of the reactive power is kept zero to ensure unit power factor operation.

Fig. 12 shows the behavior of the intermediate DC bus between the two static converters "MSC" and the "NSC", which shows a stable DC voltage to the inverter.

Fig. 13 illustrates the reactive power injected into the array by the assembly. We set ourselves a zero instruction to have a unity power factor on the network side.

Fig. 14 shows very good responses of the active power, where they follow perfectly their references with static error almost null.

Moreover, the results obtained show that the stator and rotor currents (Figs. 15, 16) have sinusoidal shapes with fewer ripples, which means a good quality of energy supplied to the network. These simulation results show that the instantaneous active and reactive powers transited in the electrical network are perfectly adjusted with respect to their references and the absorption of sinusoidal currents.

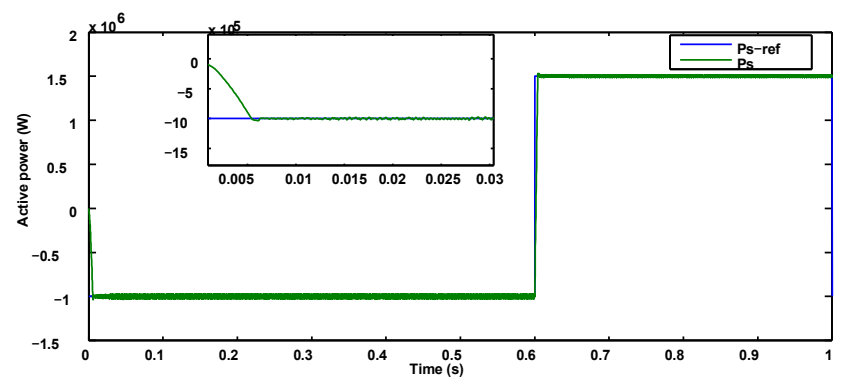

Fig. 14 DPC strategy responses (reference tracking test)

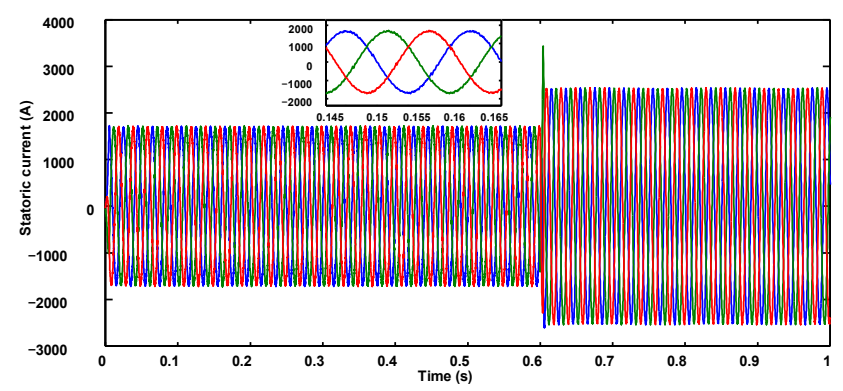

Fig. 15 DPC strategy responses

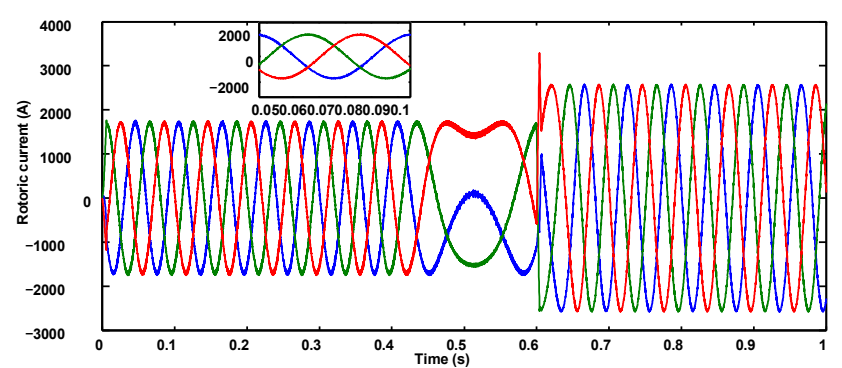

Fig. 16 DPC strategy responses 
In order to better illustrate the effect of the DPC control on the signal quality provided by the DFIG, a spectral analysis of the stator and rotor currents was performed (Fig. 17). Note that this measurement was made in the case of the operation of the variable speed wind turbine.

Fig. 18 shows that the unit Power Factor (PF) stable for DPC.

Table 3 shows the performance of control DPC. The proposed wind energy system with DPC achieved the best performance. Nevertheless, due to the fractional-order control strategy proposed in this paper, the current THD with DPC is lower than $5 \%$ limit imposed by IEEE Std 519тм-2014 [36].

\section{Conclusion}

The paper proposes a DPC scheme for a grid-connected DFIG system. The scheme is implemented on a $1.5 \mathrm{MW}$

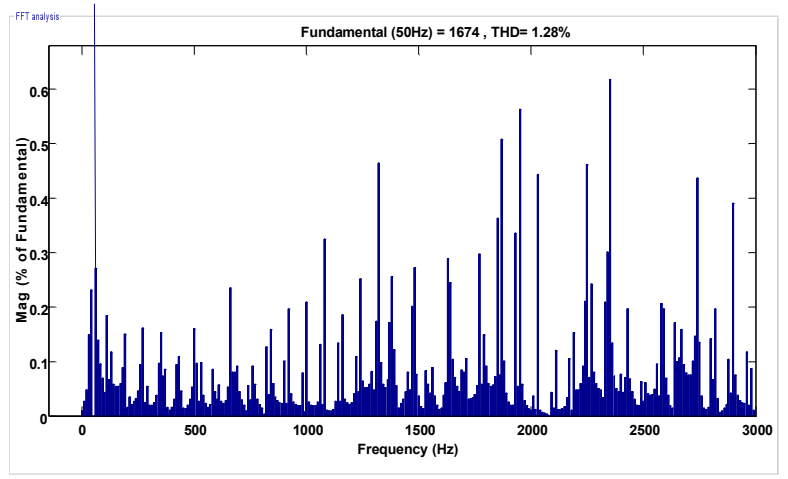

Fig. 17 Spectrum harmonic of a one-phase stator current

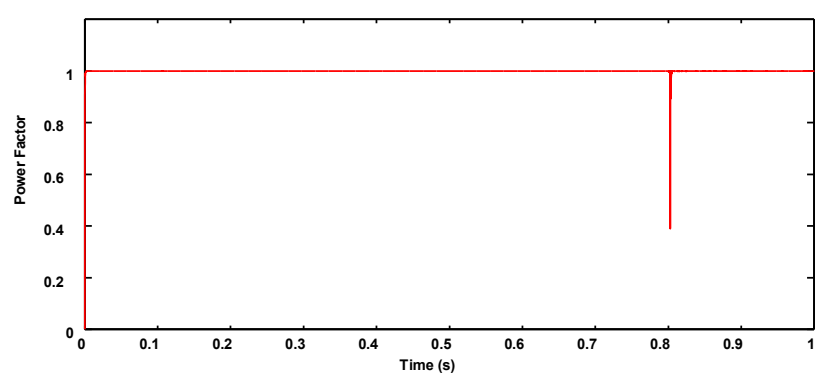

Fig. 18 Power Factor $(\mathrm{PF}=1)$

Table 3 Performances of the control DPC

\begin{tabular}{lc}
\hline Performances DPC & \\
\hline Response time (ms) & 5 \\
Active and reactive & Directly controlled \\
power control & Low \\
Computational complexity & Very good \\
Transitory response & More strong \\
Power Factor (PF) & 1.28 \\
THD $(\%)$ & \\
\hline
\end{tabular}

wind-turbine DFIG system. The MPPT strategy provides maximum active power output to the power grid through variable speed operation of the DFIG. Then, in our work, we realized the MPPT block by two controllers (PI, ANN) whose objective is to analyze their performances in terms of pursuit.

In order to control the active and the reactive powers exchanged between the Doubly Fed Induction Generator and the electrical grid used in a Wind Energy Conversion System, a control DPC is proposed. We have shown in this work the contribution of the DPC control law for the decoupling between the active and reactive power of the Doubly Fed Induction Generator. DPC provides high dynamic performance with a simple structure. It provides a concrete solution to the problems of robustness and dynamics encountered in the vector control structure. Hence, the current THD with DPC is lower than $5 \%$ limit imposed by the IEEE STANDARDS ASSOCIATION (Std 519'9M), which is used as a guideline for comparison purposes.

\section{Nomenclature}

\begin{tabular}{|c|c|}
\hline$C_{p}$ & Power coefficient \\
\hline$R$ & Blade radius (m) \\
\hline$R_{s}, R_{r}$ & Stator and rotor resistances $(\Omega)$ \\
\hline$L_{s}, L_{r}$ & Self inductance of stator and rotor $(\mathrm{H})$ \\
\hline$M$ & Mutual magnetizing inductance. \\
\hline$\varphi_{s}, \varphi_{r}$ & Stator and rotor flux $(\mathrm{Wb})$ \\
\hline$C_{e m}$ & Electromagnetic torque (Nm) \\
\hline$v$ & Wind speed $(\mathrm{m} / \mathrm{s})$ \\
\hline$J$ & Inertia moment of the moving element $\left(\mathrm{kgm}^{2}\right)$ \\
\hline$\lambda$ & Ratio of the tip speed \\
\hline$\rho$ & Air density \\
\hline$\beta$ & Pitch angle \\
\hline$\Omega$ & Mechanical speed (rad/s) \\
\hline$P$ & Active power (W) \\
\hline$Q$ & Reactive power (Var) \\
\hline MPPT & Maximum Power Point Tracking \\
\hline$f_{r}$ & Viscous friction and iron-loss coefficient. \\
\hline$p$ & Number of pair poles \\
\hline$G$ & Mechanical speed multiplier \\
\hline$\omega_{r}$ & Electrical angular rotor speed (rad/s) \\
\hline$\omega_{s}$ & Synchronously rotating angular speed $(\mathrm{rad} / \mathrm{s})$ \\
\hline$V_{s}, V_{r}$ & Stator and rotor voltage (V) \\
\hline$I_{d s}, I_{q s}$ & $\begin{array}{l}\text { Direct and quadrature component of } \\
\text { the stator currents (A) }\end{array}$ \\
\hline$I_{d r}, I_{q r}$ & $\begin{array}{l}\text { Direct and quadrature component of } \\
\text { the rotor currents }(\mathrm{A})\end{array}$ \\
\hline & Slip \\
\hline
\end{tabular}


MSC Machine Side Control

DC Direct Current
NSC Network Side Control

$\mathrm{AC} \quad$ Alternating Current

$\begin{array}{ll}\text { FFT } & \text { Fast Fourier Transform } \\ \text { PF } & \text { Power Factor } \\ \text { PLL } & \text { Phase-Locked Loop }\end{array}$

\section{References}

[1] Çadirci, I., Ermiş, M. "Double-output induction generator operating at subsynchronous and supersynchronous speeds: steady-state performance optimisation and wind-energy recovery", IEE Proceedings B (Electric Power Applications), 139(5), pp. 429-442, 1992.

https://doi.org/10.1049/ip-b.1992.0053

[2] Poitiers, F., Bouaouiche, T., Machmoum, M. "Advanced control of a doubly-fed induction generator for wind energy conversion", Electric Power Systems Research, 79(7), pp. 1085-1096, 2009. https://doi.org/10.1016/J.EPSR.2009.01.007

[3] Sinha, S., Chandel, S. S. "Prospects of solar photovoltaic-microwind based hybrid power systems in western Himalayan state of Himachal Pradesh in India", Energy Conversion and Management, 105, pp. 1340-1351, 2015.

https://doi.org/10.1016/J.ENCONMAN.2015.08.078

[4] Mazouz, L., Zidi, S. A., Hafaifa, A., Hadjeri, S., Benaissa, T. "Optimal Regulators Conception for Wind Turbine PMSG Generator Using Hooke Jeeves Method", Periodica Polytechnica Electrical Engineering and Computer Science, 63(3), pp. 151-158. 2019. https://doi.org/10.3311/PPee.13548

[5] Keshari, M., Kesari, J. P. "Concentrated Solar Power for Power Generation: (Opportunities \& Challenges)", International Journal of Advanced Research in Science, Engineering and Technologyl, 6(1), pp. 7888-7894, 2019. [online] Available at: http://www.ijarset.com/upload/2019/january/29-IJARSET-Mayank_Keshari.pdf [Accessed: 15 January 2019]

[6] Rudraraju, V. R. R., Nagamani, C., Ilango, G. S. "A control scheme for improving the efficiency of DFIG at low wind speeds with fractional rated converters", International Journal of Electrical Power \& Energy Systems, 70, pp. 61-69, 2015.

https://doi.org/10.1016/J.IJEPES.2015.01.032

[7] Mellit, A., Kalogirou, S. A., Hontoria, L., Shaari, S. "Artificial intelligence techniques for sizing photovoltaic systems: A review", Renewable and Sustainable Energy Reviews, 13(2), pp. 406-419, 2009.

https://doi.org/10.1016/J.RSER.2008.01.006

[8] Lhachimi, H., Sayouti, Y., El Kouari, Y. "Optimal improvement of direct power control strategy based on sliding mode controllers", Computers \& Electrical Engineering, 71, pp. 637-656, 2018. https://doi.org/10.1016/J.COMPELECENG.2018.08.013

[9] Takahashi, I., Noguchi, T. "A New Quick-Response and High Efficiency Control Strategy of an Induction Motor", IEEE Transactions on Industry Applications, IA-22(5), pp. 820-827, 1986. https://doi.org/10.1109/tia.1986.4504799

[10] Slotine, J.-J. E., Li, W. "Applied Nonlinear Control", 2nd ed., Prentice Hall Englewood Cliffs, New Jersey, USA, 1991.

[11] Antoniewicz, P., Kazmierkowski, M. P. "Virtual-Flux-Based Predictive Direct Power Control of AC/DC Converters With Online Inductance Estimation", IEEE Transactions on Industrial Electronics, 55(12), pp. 4381-4390, 2008. https://doi.org/10.1109/TIE.2008.2007519
[12] Parizeau, M. "Réseaux de Neurones GIF-21140 et GIF-64326" (Neural Networks GIF-21140 and GIF-64326), Université Laval, Quebec, Canada, 2004. [online] Available at: http://seborgal.free. fr/RNF.pdf [Accessed: 11 November 2018]

[13] Bakouri, A., Mahmoudi, H., Abbou, A. "Intelligent Control for Doubly Fed Induction Generator Connected to the Electrical Network", International Journal of Power Electronics and Drive System, 7(3), pp. 688-700, 2016. https://doi.org/10.11591/ijpeds.v7.i3.pp688-700

[14] Barambones, O. "Robust Wind Speed Estimation and Control of Variable Speed Wind Turbines", Asian Journal of Control, 21(2), pp. 856-867, 2019. https://oi.org/10.1002/asjc.1779

[15] Mishra, A. K., Ramesh, L. "Application of neural networks in wind power (generation) prediction", In: International Conference on Sustainable Power Generation and Supply, Nanjing, China, 2009, pp. 1-5. https://doi.org/10.1109/SUPERGEN.2009.5348160

[16] Rahimi, M. "Improvement of energy conversion efficiency and damping of wind turbine response in grid connected DFIG based wind turbines", International Journal of Electrical Power \& Energy Systems, 95, pp. 11-25, 2018. https://doi.org/10.1016/J.IJEPES.2017.08.005

[17] Boyette, A. "Contrôle-commande d'un générateur asynchrone à double alimentation avec système de stockage pour la production éolienne" (Control-command of a dual-power asynchronous generator with storage system for wind generation), $\mathrm{PhD}$ Thesis, Université Henri Poincaré, Nancy, France, 2006. (in French)

[18] Bektache, A., Boukhezzar, B. "Nonlinear predictive control of a DFIG-based wind turbine for power capture optimization", International Journal of Electrical Power \& Energy Systems, 101, pp. 92-102, 2018. https://doi.org/10.1016/J.IJEPES.2018.03.012

[19] Ghennam, T., Aliouane, K., Akel, F., Francois, B., Berkouk, E. M. "Advanced control system of DFIG based wind generators for reactive power production and integration in a wind farm dispatching", Energy Conversion and Management, 105, pp. 240-250, 2015. https://doi.org/10.1016/J.ENCONMAN.2015.07.058

[20] Belaimeche, F. Z,. Bentaallah, A., Massoum, S., Wira, P. "A comparative study between a simplified fuzzy PI and classic PI input-output linearizing controller for the wind-turbine doubly fed induction generator", Elektrotehniški Vestnik, 85(4), pp. 142-148, 2018.

[21] Boutoubat, M., Zegaoui, A., Mokrani, L., Machmoum, M. "A New control strategy for active-and reactive-power dispatching in a wind farm based on DFIG at no speed and power over-rating", Elektrotehniški Vestnik, 85(4), pp. 149-154, 2018.

[22] Manninen, V. "Application of direct torque control modulation technology to a line converter", In: 6th European Conference on Power Electronics and Applications EPE'95, vol. 1, Sevilla, Spain, 1995, pp. 1292-1296. 
[23] Attaianese, C., Tomasso, G., Damiano, A., Marongiu, I., Perfetto, A. "Direct torque and flux control of induction motor drives", In: Second International Conference on Power Electronics and Drive Systems, vol. 2, Singapore, Singapore, 1997, pp. 642-648. https://doi.org/10.1109/PEDS.1997.627435

[24] Noguchi, T., Tomiki, H., Kondo, S., Takahashi, I. "Direct power control of PWM converter without power source voltage sensors", In: IAS '96. Conference Record of the 1996 IEEE Industry Applications Conference Thirty-First IAS Annual Meeting, vol. 2, San Diego, CA, USA, 1996, pp. 941-946. https://doi.org/10.1109/IAS.1996.560196

[25] Malinowski, M., Kazmierkowski, M.P., Hansen, S., Blaabjerg, F., Marques, G. "Virtual flux based direct power control of three-phase PWM rectifiers", In: Conference Record of the 2000 IEEE Industry Applications Conference. Thirty-Fifth IAS Annual Meeting and World Conference on Industrial Applications of Electrical Energy (Cat. No.00CH37129), vol. 4, Rome, Italy, 2000, pp. 2369-2375. https://doi.org/10.1109/IAS.2000.883155

[26] Chen, Z., Spooner, E. "Grid power quality with variable speed wind turbines", IEEE Transactions on Energy Conversion, 16(2), pp. 148-154, 2001.

https://doi.org/10.1109/60.921466

[27] Shehata, E. G. "Sliding mode direct power control of RSC for DFIGs driven by variable speed wind turbines", Alexandria Engineering Journal, 54(4), pp. 1067-1075, 2015. https://doi.org/10.1016/J.AEJ.2015.06.006

[28] Rodríguez, P., Timbus, A., Teodorescu, R., Liserre, M., Blaabjerg, F. "Reactive Power Control for Improving Wind Turbine System Behavior Under Grid Faults", In: IEEE Transactions on Power Electronics, 24(7), pp. 1798-1801. 2009. https://doi.org/10.1109/TPEL.2009.2014650

[29] Amrane, F., Chaiba, A. "A hybrid intelligent control based on DPC for grid-connected DFIG with a fixed switching frequency using MPPT strategy", In: 2015 4th International Conference on Electrical Engineering (ICEE), Boumerdes, Algeria, 2015, pp. 1-4. https://doi.org/10.1109/INTEE.2015.7416678
[30] Kahla, S., Soufi, Y., Sedraoui, M., Bechouat, M. "On-Off control based particle swarm optimization for maximum power point tracking of wind turbine equipped by DFIG connected to the grid with energy storage", International Journal of Hydrogen Energy, 40(39), pp. 13749-13758, 2015. https://doi.org/10.1016/J.IJHYDENE.2015.05.007

[31] Bedoud, K., Ali-rachadi, M., Bahi, T., Lakel, R., Grid, A. "Robust Control of Doubly Fed Induction Generator for Wind Turbine Under Sub-synchronous Operation Mode", Energy Procedia, 74, pp. 886-899, 2015. https://doi.org/10.1016/j.egypro.2015.07.824

[32] Massoum, S., Meroufel, A., Massoum, A., Wira, P. "A direct power control of the doubly-fed induction generator based on the SVM Strategy", Elektrotehniški Vestnik, 84(5), pp. 235-240, 2017.

[33] Bourouina, A., Djahbar, A., Chaker, A., Boudjema, Z. "High order sliding mode direct torque control of a DFIG supplied by a fivelevel SVPWM inverter for the wind turbine", Elektrotehniški Vestnik, 85(5), pp. 263-270, 2018.

[34] Nazari, A., Heydari, H. "Direct Power Control Topologies for DFIG Based Wind Plants", International Journal of Computer and Electrical Engineering, 4(4), pp. 475-479, 2012. https://doi.org/10.7763/IJCEE.2012.V4.537

[35] Bouyekni, A., Taleb, R., Boudjema, Z., Kahal, H. "A second-order continuous sliding mode based on DPC for wind-turbine-driven DFIG", Elektrotehniški Vestnik, 85(1-2), pp. 29-36, 2018.

[36] IEEE Standards Association "IEEE Std 519'TM-2014 IEEE Recommended Practice and Requirements for Harmonic Control in Electric Power Systems", The Institute of Electrical and Electronics Engineers, Inc. (IEEE), New York, USA, 2014. [online] Available at: https:/edisciplinas.usp.br/pluginfile.php/1589263/ mod_resource/content/1/IEE\%20Std\%20519-2014.pdf [Accessed: 11 March 2018] 